Debates

Claudia de Lima Costa

Universidade Federal de Santa Catarina

\title{
Feminismos descoloniais para além do humano
}

Copyright $\odot 2014$ by Revista Estudos Feministas.

1 Claudia de Lima COSTA, 2013.

${ }^{2}$ Eduardo RESTREPO e Axel ROJAS, 2010.

\footnotetext{
${ }^{3}$ Para uma excelente discussão sobre os estudos pós-coloniais no contexto latino-americano, ver Mabel MORAÑA, Enrique DUSSEL e Carlos A. JÁUREGUI, 2008.
}

Na introdução à última seção Debate da Revista Estudos Feministas, ${ }^{1}$ discorri brevemente sobre a interseção entre estudos pós-coloniais e as teorias feministas, expondo a polissemia do prefixo "pós" (em pós-colonial) e salientando os debates na América Latina sobre o encontro entre estas duas correntes teóricas. Concluí dizendo que seria necessário dar continuidade à conversa ora iniciada explorando os feminismos descoloniais, os quais estão surgindo em vários lugares da América Latina, muitos deles situados nos desencontros entre feminismos e pós-colonialismos. Seria necessário, porém, diferenciar aqui os estudos pós-coloniais do que é geralmente referido como "a opção descolonial."

Como já sabemos, as questões que se referem à colonização da Ásia e África pelas potências do Norte europeu marcaram a genealogia dos estudos pós-coloniais. Assim sendo, para Restrepo e Rojas, ${ }^{2}$ os estudos pós-coloniais, por suas imbricações com o pós-marxismo, pós-estruturalismo e pós-modernismo (sem os quais não seriam possíveis), são vistos como distantes das preocupações da abordagem descolonial. ${ }^{3}$ Apesar de algumas afinidades entre ambos, a opção descolonial se diferencia dos estudos pós-coloniais por vários motivos: primeiro, a descolonialidade está ligada à história das Américas desde os anos 1500 até o presente. Retrepo e Rojas alegam que o lugar de enunciação da inflexão descolonial é a diferença colonial, efeito da colonização da América Latina e do Caribe pela Espanha e Portugal entre os séculos XVI e XIX; segundo, a abordagem descolonial enfatiza a continuidade das relações coloniais de poder (colonialidade do poder) através das categorias de gênero, raça e classe (como elaborarei a seguir); terceiro, a descolonialidade busca em seu projeto um desligamento das epistemologias eurocêntricas ao salientar a importância 
${ }^{4}$ Para uma abordagem sobre a produção de outros saberes feministas (e indígenas) na América Latina, ver Francesca GARGALLO, 2014.

${ }^{5}$ Walter MIGNOLO, $2012 a$, p. 29 minha tradução. Césaire e Fanon são vistos, para os/as que se identificam com o descolonial, como pensadores descoloniais, já que suas reflexões acerca do colonialismo originaram nas experiências da ferida colonial.

${ }^{6}$ MIGNOLO, 2012a, p. 26, minha tradução.

7 Ver Luciana BALLESTRIN (2013) para uma exposição bastante clara e sucinta do giro de(s)colonial na América Latina.

${ }^{8}$ MIGNOLO, 2012b.

9 RESTREPO e ROJAS, 2010.

${ }^{10}$ RESTREPO e ROJAS, 2010 , p. $37-$ 38, minha tradução. dos diferentes saberes (e paradigmas outros) sendo produzidos em diversos contextos geopolíticos, questionando assim cânones e métodos autorizado. ${ }^{4} \mathrm{~A}$ opção descolonial, partindo das epistemologias geopolíticas e biográficas/corpo-políticas (seus dois pilares) privilegia o saber fronteiriço, ou seja, aquele que "surge da exterioridade estruturada pela modernidade/ colonialidade quando esta última se constituiu como interioridade." ${ }^{5}$

A exterioridade é o lugar de residência daquela população mundial que não pertence à casa da civilização e da democracia. Assim, a modernidade é um discurso que define a sua interioridade ao criar a diferença a ser marginalizada e eliminada. A retórica da modernidade tem um vocabulário abundante para marcar a diferença, para criar exterioridade espacial e temporalmente: pagãos, bárbaros, primitivos, mulheres, gays, lésbicas, negros, índios, subdesenvolvidos, as economias emergentes, comunistas, terroristas, amarelos, etc. Todos estes serão incorporados na modernidade ou deixado de fora quando necessário. ${ }^{6}$

O projeto descolonial, em suma, busca desaprender para reaprender. ${ }^{7}$ Segundo Walter Mignolo, ${ }^{8}$ este projeto não pode ser visto como um novo método para, por exemplo, analisar um texto literário, mas sim para questionar a própria existência do conceito de literatura e da formação literária, descolonizando-os. A ferida colonial se coloca no centro da produção de conhecimento, e os sujeitos que lá se situam possuem o direito geopolítico e corpo-político de enunciação espistêmica. Em outras palavras, a descolonização do conhecimento não será possível se seu ponto de partida for o das categorias do saber ocidental. Restrepo e Rojas ${ }^{9}$ nos oferecem a seguinte definição da inflexão/opção descolonial:

É um conjunto de pensamentos críticos sobre o lado escuro da modernidadae, articulados pelos condenados da terra e que busca entender as condições de reprodução do eurocentrismo e da colonialidade do sistema-mundo. Estes, por sua vez, inferiorizam seres humanos (colonialidade do ser), dominam o mundo natural (colonialidade da natureza), constroem hierarquias de gênero (colonialidade do gênero) e hierarquizam seres e lugares a partir de uma matriz de poder global com o objetivo de melhor explorá-los para a acumulação de capital. ${ }^{10}$

Em seu artigo publicado nesta seção, Maria Lugones afirma que a hierarquia dicotômica entre o humano e o não humano é marca central da modernidade colonial. A missão civilizatória do cristianismo se concentrou na transformação do não humano colonizado em homem e mulher. $O$ não 
11 COSTA, 2014.

\footnotetext{
12 Marisol DE LA CADENA, 2010.

${ }^{13}$ Isabelle STENGERS, 2005.
}

humano feminino colonizado não foi somente racializado, mas também reinventado pela missão civilizatória como mulher por meio dos códigos de gênero ocidentais. Por isso, Lugones vê o gênero como imposição da modernidade/ colonialidade.

As discussões sobre se o gênero é ou não categoria colonial proliferaram a partir da importante intervenção de Lugones, com várias autoras apresentando argumentos a favor e contra a existência dessa categoria antes do colonialismo e da imposição do poder colonial. Não pretendo aqui explorar essa contenda, mas apenas dizer que em outro artigo ${ }^{11}$ ofereci uma possível resolução ao impasse a partir da noção de equivocação (do perspectivismo ameríndio) e do conceito de tradução, apoiando-me, respectivamente, nos escritos de de La Cadena ${ }^{12}$ e de Stengers ${ }^{13}$ sobre cosmopolítica. Adicionei a esses conceitos a mediação da tradução cultural com o propósito de explorar como seria possível conectarmos parcialmente com mundos pluriversais sem assumirmos uma comensurabilidade entre eles; ou seja, como feministas das mais variadas correntes e localizações geopolíticas e corpo/políticas poderiam forjar coalizações entre mundos e ontologias radicalmente diferentes sem reduzi-los a equivalências. Quis argumentar que a tradução, incluindo a tradução performática, se torna um importante elemento mediador nesta tarefa e que urge ser incorporada aos debates sobre feminismos descoloniais e sobre mundos pluriversais com suas respectivas cosmologias, ontologias e saberes outros.

Como exemplo do acima dito, perscrutando em torno do tropo da tradução, as colaboradoras da antologia Translocalities/Translocalidades: Feminist Politics of Trans/ation in the Latin/a Américas ${ }^{14}$ examinam de que forma nos feminismos das Américas Latin/as tanto tradução (e sua política) quanto transculturação a partir de diversas translocalidades podem contribuir para a construção de "epistemologias conectantes" 15 e forjar alianças políticas antirracistas, antiimperialistas e descoloniais. Para Sonia E. Alvarez,16

Uma conceitualização [...] da transculturação - que promove processos tanto intraculturais quanto transculturais de transformação multidirecional e processos de vários níveis de "desculturação" e re-fundação cultural - também objetiva interromper e re-engajar a teorização contemporânea sobre a colonialidade do poder e a interculturalidad ou interculturalidade. Como proposto por Norma Klahn, ${ }^{17}$ para melhor entender a "colonialidade do poder" deve-se começar pela compreensão das traduções e viagens desiguais das práticas, teorias e textos feministas e sua recepção.

Gostaria de salientar, com as autoras da antologia acima referida, que saberes são sempre resultado de 
${ }^{18}$ Mary Louise PRATT, 1992.

19 Ver Pal Ahluwalia (2005) para uma discussão instigante sobre as "raízes" africanas do pósestruturalismo.

${ }^{20}$ Emily APTER, 2006.

${ }^{21}$ Ana Rebeca PRADA, 2014.
${ }^{22}$ Mujeres Creando é um movimento feminista autônomo criado em 1992, em La Paz, Bolívia, e formado por mulheres de diferentes origens culturais e sociais. Enfoca a criatividade como instrumento de luta e participação social.

23 Gloria ANZALDÚA, 1987.

${ }^{24}$ PRADA, 2014, p. 73. processos de transculturação, isto é, de negociações interculturais características da zona de contato. ${ }^{8}$ É extremamente difícil apontar a origem de um saber e suas múltiplas hibridizações, já que saberes sempre surgem nesses espaços assimétricos de relações de poder e são apropriados, traduzidos, ressignificados e redistribuídos, subvertendo qualquer visão binária entre Ocidente e seus outros. ${ }^{19} \mathrm{O}$ que quero apontar com isso é a necessidade de refletirmos sobre os processos de tradução do conhecimento e de suas categorias nas zonas de contato/zonas de tradução ${ }^{20}$ e a partir da ferida colonial.

Por exemplo, Prada, ${ }^{21}$ discorrendo sobre a circulação dos escritos de Anzaldúa no contexto plurinacional boliviano, explica que qualquer tradução, sem uma adequada mediação, corre o risco de se tornar uma dupla traição: primeiro, traição que qualquer tradução já necessariamente implica em relação ao dito original e, segundo, traição diante da apropriação do texto traduzido como parte de um sofisticado aparato teórico proveniente do Norte. O trabalho de mediação se faz necessário para que a tradução desses textos, provenientes de outras latitudes no Norte, possam dialogar com textos e práticas locais, assim contestando as formas pelas quais o Sul é consumido e conformado pelo Norte - integrando a crítica em diálogos não apenas NorteSul, mas também Sul-Sul. Prada analisa de forma instigante como o grupo de feministas anarquistas bolivianas, Mujeres Creando ${ }^{22}$ - que se autodescrevem como cholas, chotas e birlochas (termos racistas usados em referência a mulheres indígenas imigrantes nas cidades) e que também adotam outras designações de subjetividades abjetas (tais como puta, rechazada, desclasada, extranjera) -, dialogaram com Anzaldúa ao transportar Borderlands/La Frontera ${ }^{23}$ para um contexto de política feminista além dos muros da academia (onde Anzaldúa havia sido inicialmente lida), estabelecendo afinidades entre os dois projetos políticos. Assim sendo, a linguagem de Anzaldúa, enunciada ao Sul do Norte, foi apropriada pelo Sul do Sul e "incorporada de fato a um feminismo transnacional sem fronteiras a não ser aquelas que o patriarcado, o racismo e a homofobia insistem em demarcar". ${ }^{24}$ Conforme explica Prada,

Traduzir então, se torna algo muito mais complexo. Tem a ver com tradução linguística, sim, mas também com disponibilizar um trabalho (com todas as consequências que isso implica, com todas as traições e apagamentos que possa incluir) para outros públicos e deixá-lo viajar. Tem a ver também com a abertura de espaços de conversação e de novos horizontes para o diálogo. Significa também abrir suas escolhas, seus gostos, suas afinidades com os/as outros/as, o que na política (como 
25 PRADA, 2014, p. 73-74, minha tradução. com Mujeres Creando) pode comprometer (ou fortalecer) seus princípios. A tradução nesses termos se faz rigorosamente seletiva e estratégica. ${ }^{25}$

Concluo esta breve apresentação à seção Debate lembrando que, para Lugones (e certamente para as feministas latinas e latino-americanas que contribuíram para a Trans/ocalities/Trans/ocalidades), a resistência à colonialidade do gênero implica, entre outras coisas, resistência linguística e, diria também, mediação e resistência tradutória. Significa colocar os paradigmas de representação eurocêntricos, com ancoragem na lógica dicotômica, sob rasura. Sem abrir mão da categoria (sempre equívoca) do gênero, mas articulando-a de forma que desafie os binarismos perversos da moderni-dade/colonialidade, talvez possamos nos juntar àquelas feministas - latino-americanas, latinas, negras, indígenas e feministas ocidentais situadas nas ciências (ditas) exatas, entre outras - para repensar as fronteiras coloniais entre humano e não humano, matéria e discurso que estruturaram a coloni-alidade do gênero e a colonialidade do poder. Ao rompermos essas fronteiras, estaremos certamente iniciando uma nova fase descolonial (o feminismo antropoceno?), convidando (ou sendo obrigadas a receber) outros entes além do humano para a interlocução.

\section{Referências}

AHLUWALIA, Pal. "Out of Africa: Post-Structuralism's Colonial Roots." Postcolonial Studies, v. 8, n. 2, p. 137-154, 2005.

ALVAREZ, Sonia E.; COSTA, Claudia de Lima; FELIU, Veronica; HESTER, Rebecca; KLAHN, Norma; THAYER, Millie (Eds.). Trans/ocalities/Translocalidades: Feminist Politics of Translation in the Latin/a Américas. Durham: Duke University Press, 2014.

ALVAREZ, Sonia E. "Constituindo uma política translocal da tradução". Revista Estudos Feministas, v. 17, n. 3, p. 743753, 2009.

ANZALDÚA, Gloria. Borderlands/La Frontera: The New Mestiza. San Francisco: Spinsters/Aunt Lute Books, 1999[1987].

APTER, Emily. The Trans/ation Zone: A New Comparative Literature. Princeton: Princeton University Press, 2006.

BALLESTRIN, Luciana. América Latina e o giro decolonial. Revista Brasileira de Ciência Política, n. 11, p. 89-117, 2013.

COSTA, Claudia de Lima. Equivocação, tradução e interseccionalidade performativa: observações sobre ética e prática feministas descoloniais. In: BIDASECA, Karina; OTO, Alejandro de; OBARRIO, Juan; SIERRA, Marta (Comps.). Legados, genealogías y memorias poscoloniales en América Latina: Escrituras fronterizas desde el Sur. Buenos Aires: Ediciones Godot/Colección Crítica, 2014. p. 275-307. 
COSTA, Claudia de Lima. "Feminismos e pós-colonialismos." Revista Estudos Feministas, v. 21, n. 2, p. 655-658, 2013.

DE LA CADENA, Marisol. "Indigenous Cosmopolitics in the Andes: Conceptual Reflections Beyond 'Politics'". Cultural Anthropology, v. 25, n. 2, p. 334-370, 2010.

GARGALLO, Francesca. Feminismos desde Abya Yala: Ideas y proposiciones de las mujeres de 607 pueblos en nuestra América. Ciudad de México: Editorial Corte y Confección (1a Edición Digital: http://francescagargallo.wordpress. com), 2014.

LÁO-MONTES, Agustín. "Afro-Latinidades: Bridging Blackness and Latinidad." In: MIRABAL, Nancy R.; LÁO-MONTES, Agustín (Eds.). Technofuturos: Critical Interventions in Latino/a Studies. New York: Lexington Books, 2007. p. 117-140.

MIGNOLO, Walter. Decolonizing Western Epistemology/Building Decolonial Epistemologies. In: ISASI-DÍAZ, Ada María; MENDIETA, Eduardo (Eds.). Decolonizing Epistemologies: Latina/o Theology and Philosophy. New York: Fordham University Press, 2012a. p. 19-43.

."The Prospect of Harmony and the Decolonial View of the World." Marxism and Reality, v. 4, p. 110-120. 2012b.

PRADA, Ana Rebeca. "Is Anzaldúa Translatable in Bolivia?" In: ALVAREZ, Sonia E.; COSTA, Claudia de Lima; FELIU, Veronica; HESTER, Rebecca; KLAHN, Norma; THAYER, Millie (Eds.). Translocalities/Translocalidades: Feminist Politics of Trans/ation in the Latin/a Américas. Durham: Duke University Press, 2014. p. 57-77.

PRATT, Mary L. Imperial Eyes: Travel Writing and Transculturaltion. New York: Routledge, 1992.

RESTREPO, Eduardo; ROJAS, Axel. Inflexión decolonial: Fuentes, conceptos y cuestionamientos. Popayán, Colombia: Editorial Universidad del Cauca, 2010.

STENGERS, Isabelle. "The Cosmopolitical Proposal". In: LATOUR, Bruno; WEIBEL, Peter (Eds.). Making Things Public: Atmospheres of Democracy. Cambridge: MIT Press, 2005. p. 994-1004. 